Available online at https://jurnal.stmikroyal.ac.id/index.php/jurdimas

\title{
EDUKASI BUDAYA JAJAN SEHAT PADA SISWA-SISWI SDN JATINANGOR (ANALISIS SITUASIONAL DAN RENCANA SOLUSI)
}

\author{
Tania Intan $^{* 1}$, Vincentia Tri Handayani ${ }^{2}$, Ferli Hasanah ${ }^{3}$ \\ ${ }^{1,2,3}$ Program Studi Sastra Prancis, Fakultas Ilmu Budaya, Universitas Padjadjaran \\ Jl. Raya Bandung-Sumedang Km. 21,7 Jatinangor \\ email :*tania.intan@unpad.ac.id
}

\begin{abstract}
This article is a situational analysis of the 'snack culture' especially for Jatinangor Elementary School students. To answer the problems regarding snack culture that have an impact on health, a solution plan has been prepared by the Community Service team from Padjadjaran University consisting of three lecturers and five students. The series of activities which are educational interventions will be carried out using counseling methods and games. PKM activities are carried out in three stages, namely the preparation stage, the implementation stage, and the evaluation and reporting stages. The results of the interim study show that children's snack culture needs to get attention from parents and schools. Parents have the power to influence and control these habits, while schools can make policies regarding snacks that can be consumed by their students.
\end{abstract}

Keywords: Snack Culture, Healthy Food, Situational Analysis, Solution Plan

\begin{abstract}
Abstrak: Artikel ini merupakan analisis situasional mengenai 'budaya jajan' khususnya pada siswa SDN Jatinangor. Untuk menjawab permasalahan mengenai budaya jajan yang berdampak pada kesehatan, telah disusun rencana solusi oleh tim pelaksana Pengabdian Kepada Masyarakat dari Universitas Padjadjaran yang terdiri dari tiga orang dosen dan lima orang mahasiswa. Rangkaian kegiatan yang merupakan intervensi edukatif akan dilakukan dengan menggunakan metode penyuluhan dan permainan. Kegiatan PKM dilakukan dalam tiga tahap, yaitu tahap persiapan, tahap penyelenggaraan, dan tahap evaluasi dan pelaporan. Hasil kajian sementara menunjukkan bahwa budaya jajan anak perlu mendapatkan perhatian dari orang tua dan sekolah. Orang tua memiliki kuasa untuk mempengaruhi dan mengendalikan kebiasaan tersebut, sedangkan sekolah dapat membuat kebijakan mengenai jajanan yang dapat dikonsumsi para siswanya.
\end{abstract}

Kata kunci: Budaya jajan, makanan sehat, analisis situasional, rencana solusi

\section{PENDAHULUAN}

Makanan yang bersih, sehat, dan bergizi seimbang sangat dibutuhkan pada masa kanak-kanak karena digunakan untuk proses pertumbuhan dan perkembangan. Makanan yang dikonsumsi anak-anak ini tidak selalu didapatkan dari rumah namun juga berupa kudapan yang diperoleh dari lingkungan luar rumah, misalnya di jalanan atau kantin sekolah. Karena dianggap lebih menarik, harganya terjangkau, dan juga rasanya lebih 
Available online at https://jurnal.stmikroyal.ac.id/index.php/jurdimas

enak, anak-anak cenderung memilih jajanan dan melewatkan makanan utama. Kenyataannya, mereka yang tidak sarapan dengan berbagai alasan seperti bangun kesiangan atau makanan yang disediakan orang tua tidak menarik- cenderung memiliki energi dan zat gizi yang lebih sedikit daripada mereka yang sarapan (Briawan, 2016: 201-202).

Makanan jajanan (street food) lebih dikenal sebagai snack, dan umumnya didefinisikan sebagai makanan atau kudapan yang diproduksi sendiri pada tingkat rumah tangga maupun yang dipersiapkan untuk konsumsi langsung di lokasi penjualan yang terdapat di pinggir jalan atau di tempattempat umum, Jajanan biasanya dijajakan dengan cara berkeliling (Judarwanto, 2008: 15). Kebiasaan jajan, menurut pendapat Suhardjo (1989: 15) yang dikutip Sari (2017: 34), merupakan istilah untuk menggambarkan kebiasaan dan perilaku yang berhubungan dengan makan dan makanan, seperti frekuensi makan, jenis makanan, preferensi terhadap makanan, dan cara pemilihan makanan. Di lingkungan sekolah, jajan sering dilakukan siswa-siswi saat jam istirahat sekolah atau saat pulang. Mereka biasanya pergi ke kantin sekolah untuk membeli jajanan karena merasa lapar dan haus, atau sekedar untuk mengobrol. Kebiasaan siswa membeli jajanan di kantin sekolah telah membudaya mulai dari siswa tingkat sekolah dasar hingga tingkat lanjutan atas. Anak-anak sebagai konsumen utama jajanan sering kali tidak tahu atau tidak memperhatikan keamanannya. Mereka cenderung membeli jajanan hanya sesuai kesukaannya, tanpa mempertimbangkan kebersihan dan kesehatan. Kebiasaan mengonsumsi makanan oleh anakanak dimulai dari kebiasaan di dalam keluarga, masyarakat sekitar, dan juga dari lingkungan sekolah.

Kebiasaan jajan di sekolah sangat bermanfaat jika makanan yang dibeli itu sudah memenuhi syarat-syarat kesehatan, sehingga dapat melengkapi atau menambah kebutuhan gizi anak. Disamping itu juga untuk mencegah kekosongan lambung, karena setiap 3-4 jam sesudah makan, anak akan me- rasa lapar. Menurut Yusuf dkk. (2008) yang dikutip oleh Mavidayanti \& Mardiana (2016: 71), apabila anak merasa lapar, akan berpengaruh terhadap konsentrasinya sehingga anak tidak dapat memusatkan kembali pikirannya pada pelajaran yang diberikan oleh guru di kelasnya.

Meskipun demikian, banyak juga permasalahan yang ditimbulkan dari kebiasaan jajan ini. Berdasarkan penelitian Nuryani \& Rahmawati (2018: 114), ada kaitan antara kebiasaan jajan dengan status gizi anak-anak. Gagasan tersebut mendukung pendapat Fadli (2013) yang dikutip Hastutik \& Putri (2018: 162) bahwa masalah gizi kerap terjadi pada anak-anak pada usia sekolah dasar, berupa obesitas, gagal tumbuh, anemia karena kekurangan zat besi, karies pada gigi geligi, serta infeksi kecacingan.

Bagaimanapun juga perilaku jajan telah membudaya dan menjadi bagian dari keseharian hampir semua kelompok usia dan kelas sosial, termasuk anak usia sekolah dan golongan remaja. Menurut Syah (2005) yang dikutip Yulianto dkk (2014: 2), hampir semua anak usia sekolah gemar jajan (mencapai 95\%-96\%). Akan tetapi, menurut Judarwanto (2009) yang dikutip Mavidayanti \& Mardiana (2016), makanan jajanan di sekolah ternyata sangat berisiko mendapatkan cemaran biologis atau kimiawi yang mengganggu kesehatan. Selain nilai gizi makanan jajanan yang relatif rendah, keamanan pangan makanan jajanan juga menjadi masalah. Kurangnya perhatian dari berbagai kalangan terhadap hal ini sering mengakibatkan terjadinya dampak berupa penurunan kesehatan konsumennya, mulai dari keracunan makanan akibat tidak higienisnya proses penyimpanan dan penyajian, sampai risiko munculnya penyakit kanker akibat penggunaan bahan tambahan (food additive) yang berbahaya.

Penelitian BPOM (Badan Pengawas Obat dan Makanan) pada tahun 2008 yang dikutip Briawan (2016: 202) menyatakan bahwa $45,0 \%$ pangan jajanan anak sekolah tidak memenuhi syarat karena mengandung zat kimia berbahaya seperti formalin, boraks, rodamin, dan Bahan Tambahan Pangan 
Available online at https://jurnal.stmikroyal.ac.id/index.php/jurdimas

(BTP) seperti siklamat dan benzoate yang melebihi batas aman, serta akibat cemaran mikro-biologi.

Yulianto dkk. (2014:1) juga mengutip Oktaviani (2010) yang mengemukakan adanya dampak jangka pendek yang dapat ditimbulkan dari penggunaan beberapa zat pewarna pada makanan, terutama zat pewarna sintetis tekstil antara lain urtikaria (ruam kulit), rhinitis (hidung meler), asma, purpura (kulit lebam) dan anafilaksis sistemik (shock). Sedangkan zat pewarna makanan berupa Tartrazine (E102 atau Yellow 5) dan Quinoline Yellow (E104) berpotensi meningkatkan hiperaktivitas anak dan serangan asma.

Untuk menghindari hal-hal yang tidak diinginkan tersebut terjadi, diperlukan perhatian dan pengawasan dari berbagai pihak, khususnya orang tua dan sekolah. Orang tua [memiliki kuasa untuk] mempengaruhi pemilihan makanan anak dengan mengendalikan ketersediaan makan, berperan sebagai pemberi contoh, dan mendorong anak untuk mengkonsumsi makanan tertentu. Pengetahuan tentang gizi yang dimiliki orang tua tentunya akan berpengaruh terhadap pemilihan makan anak. Minimnya pendidikan gizi yang dimiliki orang tua menyebabkan rendahnya pengetahuan gizi yang dimiliki oleh anak (Sembiring, 2018: 52). Untuk meningkatkan pengetahuan serta mengubah perilaku dan praktik budaya jajan anak-anak, diperlukan adanya intervensi edukasi.

Tim pelaksana PKM dari Universitas Padjadjaran bermaksud untuk berpartisipasi dalam usaha mengentaskan permasalahan budaya jajan pada anak-anak ini dengan cara menyelenggarakan kegiatan edukasi. Lokasi kegiatan dipilih di wilayah Kecamatan Jatinangor, yaitu SDN Jatinangor, dengan pertimbangan keterjangkauan dan kemudahan mobilitas tim pelaksana PKM. Di kemudian hari, program serupa akan dilaksanakan di sekolah-sekolah dasar lainnya khususnya yang ada di sekitar kampus.

Penelitian-penelitian terdahulu yang relevan dan menjadi dasar penyelenggaraan PKM ini di antaranya telah dilakukan oleh Bryawan (2016) mengenai Perubahan Penge- tahuan, Sikap, dan Praktik Jajanan Anak Sekolah Dasar Peserta Program Edukasi Pangan Jajanan, Febryanto (2016) yang membahas Hubungan Antara Pengetahuan dan Sikap dengan Perilaku Konsumsi Jajanan di MI Sulaimaniyah Jombang, dan Hastutik \& Putri (2018) yang menyusun Deskripsi Kebiasaan Jajan Pada Anak Sekolah Dasar Negeri 03 Kragilan Mojolaban Sukoharjo.

\section{METODE}

Pengabdian Kepada Masyarakat yang akan dilakukan berupa kegiatan edukasi dengan metode penyuluhan dan permainan dengan khalayak sasaran 30 orang siswa SD dari kelas 1-2 dan 2 orang guru pendamping. Tim pelaksana terdiri dari 3 orang dosen dan 5 orang mahasiswa.

Secara sistematis, kegiatan PKM (Pengabdian Kepada Masyarakat) dilaksanakan dalam tiga tahap yaitu:

1. Persiapan,

2. Penyelenggaraan,

3. Evaluasi dan pelaporan.

Tahap persiapan di antaranya terdiri dari kegiatan rapat-rapat pembentukan tim pelaksana dan rincian tanggung jawab masing-masing, serta survey lapangan. Tahap penyelenggaraan merupakan realisasi dari rencana kerja yang telah dipersiapkan, dan dilakukan di lapangan/ lokasi kegiatan yaitu SDN Jatinangor. Sedangkan tahap evaluasi dan pelaporan merupakan langkah-langkah administratif berupa pencatatan atas hasil penyelenggaraan dalam bentuk laporan dan penyusunan artikel ilmiah.

\section{PEMBAHASAN}


Available online at https://jurnal.stmikroyal.ac.id/index.php/jurdimas

Menurut data yang didapatkan dari website Data Pokok Pendidikan Dasar dan Menengah (2019), diketahui bahwa SD Jatinangor yang berakreditasi B ini dipimpin oleh kepala sekolah bernama Ibu Ratnasih. Kegiatan belajar mengajar dilakukan pada pagi hari dengan menggunakan Kurikulum 2013.

Tabel 1. Identitas Sekolah

\begin{tabular}{ll}
\hline NPSN & 20233901 \\
\hline Status & Negeri \\
\hline $\begin{array}{l}\text { Bentuk Pen- } \\
\text { didikan }\end{array}$ & SD \\
\hline $\begin{array}{l}\text { Status } \\
\text { Kepemilikan }\end{array}$ & Pemerintah Daerah \\
\hline $\begin{array}{l}\text { SK Pendirian } \\
\text { Sekolah }\end{array}$ & $422 / 2894 /$ Dikbud/2016 \\
\hline $\begin{array}{l}\text { Tanggal SK } \\
\text { Pendirian }\end{array}$ & $2016-08-02$ \\
\hline $\begin{array}{l}\text { SK Izin } \\
\text { Operasional }\end{array}$ & $422 / 2894 /$ Dikbud/2016 \\
\hline $\begin{array}{l}\text { Tanggal SK } \\
\text { Izin } \\
\text { Operasional }\end{array}$ & $2016-08-02$ \\
\hline
\end{tabular}

Tabel 2. Kontak Utama Lokasi Kegiatan

\begin{tabular}{ll}
\hline Alamat & Dusun Caringin \\
\hline RT / RW & $4 / 12$ \\
\hline Dusun & Caringin \\
\hline Desa/Kelurahan & Sayang \\
\hline Kecamatan & Jatinangor \\
\hline Kabupaten & Sumedang \\
\hline Provinsi & Jawa Barat \\
\hline Kode Pos & 45363 \\
\hline Lintang & -6.9406000 \\
\hline Bujur & 107.7706000 \\
\hline
\end{tabular}

SDN Jatinangor seperti sekolah-sekolah dasar pada umumnya memiliki kantin sekolah. Namun demikian, kondisinya belum dapat disebut sehat dan beragam. Demikian pula dengan jajanan yang tersedia di jalanan di depan sekolah.
Penyuluhan sebagai bentuk edukasi kepada para siswa menjadi penting untuk dilakukan agar mereka mengenal dan mengetahui kriteria jajanan sehat dan ragamnya. Menurut Oktavianawati (2017: vii), jajanan tradisional [dibandingkan dengan jajanan modern atau fast food] merupakan jajanan yang sehat karena terbuat dari bahan-bahan alami seperti tepung beras dan tepung ketan, serta tidak mengandung bahan pengawet. Banyak anak Indonesia saat ini tidak lagi mengenal akrab penganan tradisional. Mereka umumnya lebih menyukai roti, pizza, atau burger yang dijual secara berkeliling dengan harga murah namun tidak terjamin kesehatan dan kebersihannya. Kelebihan lain dari jajanan tradisional adalah bahannya mudah diperoleh.

Para siswa perlu diperkenalkan kembali pada kue-kue tradisional yang dapat menjadi alternatif jajanan yang sehat. Beberapa di antara kue-kue itu adalah: kue Ape, kue Klepon, kue Putu, kue Pancong, Gulali, bubur sumsum, kerak telur, kue Rangi, Getuk, Arum Manis, dan kue Cenil. Dengan menggunakan referensi mengenai jajanan tradisional asli Indonesia dari Oktavianawati (2017), tim pelaksana PKM akan menayangkan gambar dan memberikan penjelasan mengenai kue-kue tersebut, dan bila memungkinkan, membawa berbagai jenis kue tersebut untuk dicicipi bersama.

Seupan (umbi-umbian seperti ubi, singkong, talas, kacang-kacangan, dan buah seperti pisang dan labu yang dikukus) merupakan jajanan tradisional masyarakat Sunda yang sedang direvitalisasi keberadaannya (Oda, 2017: 1). Makanan yang murah meriah ini tidak menggunakan bahan pengawet, pewarna, dan perasa, sehingga dianggap menyehatkan. Gerakan kembali ke makanan tradisional ini juga berkaitan dengan konteks ekonomi dan kepariwisataan.

Selain lebih sehat, para siswa juga perlu diingatkan bahwa jajanan tradisional merupakan warisan budaya kuliner bangsa yang perlu dilestarikan bersama. Para siswa akan diajak untuk berpartisipasi dalam upaya ini dengan cara: membeli jajanan tradisional, belajar membuat jajanan tradisional sendiri, 
Available online at https://jurnal.stmikroyal.ac.id/index.php/jurdimas

mengajak teman untuk membeli jajanan tradisional, dan menjelaskan keunggulan jajanan tradisional kepada teman-teman. Upaya sosialisasi dan revitalisasi jajanan tradisional pernah dilakukan dengan menggunakan teknologi informatika yang dilakukan Udin dkk. (2016) dengan aplikasi games. Permainan interaktif ini dirancang untuk menarik minat anak-anak dalam melakukan wisata kuliner jajanan tradisional.

Jajanan tradisional juga dapat bertambah nilai jualnya bila diberikan sentuhan kreativitas, seperti yang diungkapkan oleh Syarifuddin (2018) yang membahas tentang kue Surabi khas Bandung. Kue ini dapat divariasikan dalam 20 rasa dengan topping yang berbeda-beda. Meskipun demikian, originalitas Surabi masih dipertahankan pada aspek bahan dasar yaitu tepung beras dengan menggunakan tungku pembakar dan cetakan tanah liat.

Selain terbuat dari bahan alami dan tidak mengandung zat pengawet, jajanan sehat juga tidak seharusnya dimasukkan ke dalam plastik dalam kondisi panas (Hastutik \& $\mathrm{Pu}$ tri, 2018: 164). Dalam kenyataannya, saat ini anak-anak gemar menggunakan plastik sebagai wadah untuk mengonsumsi makanan seperti gorengan, seblak, cilok, cimol, dan sebagainya.

Plastik mengandung berbagai bahan kimia berbahaya bagi tubuh manusia, seperti polietilen, polivinil klorida, dan polistiren. Jika seseorang sering mengkonsumsi makanan yang diletakkan di dalam plastik, apalagi dalam jangka waktu panjang, maka orang tersebut memiliki resiko yang tinggi untuk mengalami gangguan kesehatan berat. Hal ini terjadi karena saat makanan panas dimasukkan ke dalam plastik, ada pencampuran di antara bahan kimia dari plastik dan makanan.

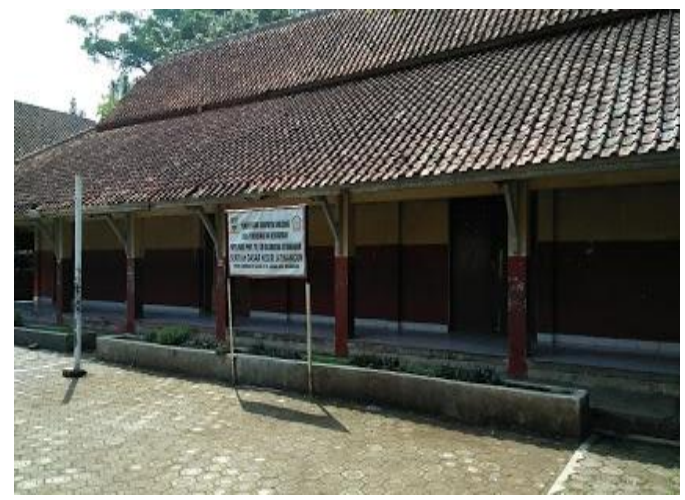

Gambar 1. SDN Jatinangor

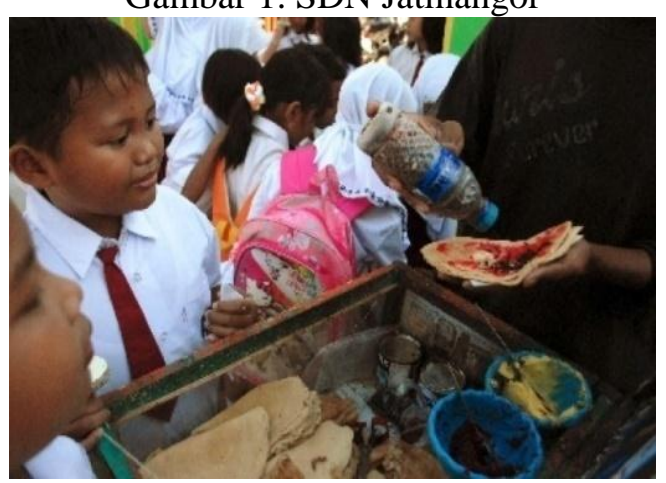

Gambar 2. Ilustrasi Jajanan di Sekolah

Sarana dan prasarana yang dibutuhkan untuk kegiatan penyuluhan ini di antaranya: tempat berupa ruangan yang besar/ lapangan, 1 buah komputer, 1 buah proyektor, dan 1 buah layar. Selain itu, perlu disediakan pula hadiah-hadiah untuk siswa-siswi yang dapat menjawab pertanyaan yang sewaktu-waktu diajukan pemberi materi.

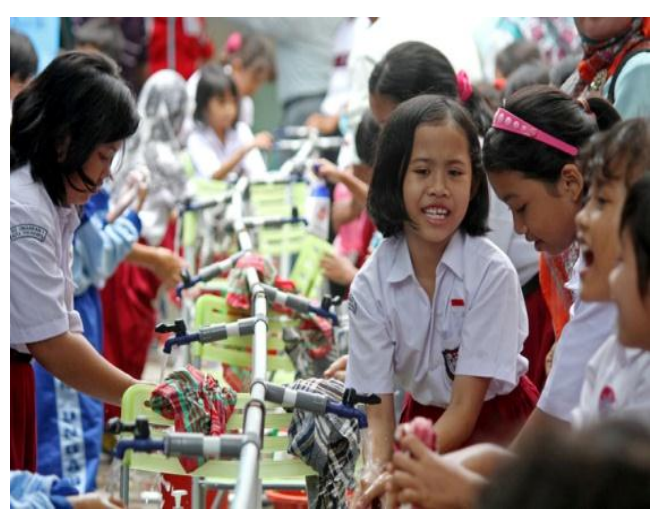

Gambar 3. Ilustrasi Siswa-siswi SD Cuci Tangan 
Available online at https://jurnal.stmikroyal.ac.id/index.php/jurdimas

Kegiatan PKM yang akan dilaksanakan ini juga akan mengapropriasi sejumlah permainan menarik yang telah dirancang oleh Nugroho dkk. (2012). Permainan-permainan ini ditujukan untuk mengedukasi siswa-siswi SD tentang pentingnya mengadopsi budaya jajan yang sehat. Permainan-permainan yang akan dilakukan dalam kegiatan PKM ini di antaranya adalah:

\section{Mencari kuman di tangan}

Alat yang diperlukan: senter UV, bubuk glitter putih, dan bola. Cara bermain: anakanak dibagi menjadi beberapa kelompok. Sebuah bola dilumuri glitter bubuk. Instruktur melempar bola kepada anak-anak, kemudian anak-anak saling menangkap dan melempar yang dilakukan sambil bernyanyi atau melakukan permainan tertentu. Setelah puas bermain, tangan mereka disinari dengan senter UV. Bubuk yang menempel di tangan dianggap seperti kuman.

Manfaat permainan: mendidik bahwa kontaminasi bisa terjadi pada makanan, sehingga jika ada teman yang sakit, sebaiknya tidak berbagi makanan dalam satu wadah. Pemateri dan fasilitator juga mengingatkan bahwa kuman tidak terlihat, namun ada. Oleh karena itu penting untuk selalu mencuci tangan sebelum makan.

\section{Memilih makanan sehat dan halal}

Alat yang diperlukan: kartu-kartu bergambar jajanan yang sehat dan tidak sehat, 2 boks atau poster untuk menempel atau meletakkan kartu-kartu tersebut.

Cara bermain: anak-anak dibagi menjadi 2 tim atau lebih. Kartu dikocok. Anak-anak diberi waktu dan kesempatan untuk berpikir dan meletakkan kartu di boks atau menempelnya di poster sesuai dengan kategorinya (sehat atau tidak). Kelompok pertama yang melengkapi poster menjadi pemenangnya.

Manfaat permainan: anak-anak dapat mengenal mana jajanan yang sehat atau tidak sehat, mengenal bahaya dan resiko masingmasing jajanan yang dimakan dan dipilihnya.

\section{Mengenal makanan daerah}

Alat yang diperlukan: peta Indonesia dan kartu makanan Indonesia.

Cara bermain: anak-anak dibagi menjadi beberapa kelompok. Kartu makanan daerah beserta peta dibagikan. Anak-anak harus menyebutkan nama makanan, kemudian meletakkan kartu di peta untuk menunjukkan dari daerah asal makanan tersebut. Pemenang adalah kelompok yang paling dulu dan benar meletakkan kartu di peta.

Manfaat permainan: anak-anak dapat mengenal makanan daerah, potensi lokal daerah, dan nama-nama daerah di Indonesia.

4. Mencocokkan fungsi makanan dan nutrisi Alat yang diperlukan: kartu makanan, kartu fungsi makanan dalam tubuh (misalnya karbohidrat, vitamin, dsb.), papan untuk menempel, paku payung/pin, dan tali kenur. Cara bermain: anak-anak dibagi menjadi beberapa kelompok. Kartu dikocok. Kartu sebelah kiri dan kanan dicocokkan, kanan adalah fungsi, sedangkan kiri adalah jenis atau nama makanannya atau foto makanan. Tali kenur warna-warni dipasang untuk menunjukkan hubungan antara makanan dan fungsinya. Cara lain, bisa juga masingmasing memegang kartu, kemudian saling berpasangan membentuk kelompok kecil lagi berdasarkan fungsinya.

Manfaat permainan: anak-anak dapat mengenal jenis makanan dan fungsinya, proporsi makanan dan mengetahui bahwa makan harus seimbang dan beragam.

\section{Daftar makanan dari pangan lokal}

Alat yang diperlukan: pensil atau alat tulis, papan atau kertas untuk mencatat.

Cara bermain: anak-anak dibagi menjadi beberapa kelompok kecil. Setiap kelompok harus menuliskan ide makanan yang bisa dibuat dari bahan pangan lokal, misalnya: dari ubi, singkong, atau pisang, atau lainnya. Yang paling kreatif dan membuat daftar yang paling banyak adalah pemenangnya.

Manfaat permainan: dapat mengasah kreativitas, memberi pemahaman bahwa pangan lokal dapat dibuat menjadi berbagai makanan yang enak dan lezat.

6. Mengenal zat berbahaya dari pangan 
Available online at https://jurnal.stmikroyal.ac.id/index.php/jurdimas

Alat yang diperlukan: pewarna makanan, pengawet makanan dalam bentuk foto atau secara fisik. Jika makanan dibawa wujud yang sesungguhnya maka lebih baik. Harus disiapkan juga $\mathrm{H} 2 \mathrm{SO} 4$ pekat, bunsen, cawan, dan alkohol.

Cara bermain: anak-anak dibagi menjadi beberapa kelompok. Masing-masing kelompok mencoba meneteskan pewarna yang berbahaya dan yang alami ke dalam larutan atau adonan. Kemudian dibahas perbedaan di antara keduanya. Mereka juga dapat diminta mencari jajanan lain atau mencoba pada sampel yang sudah sengaja diberi borax. Kupas kunyit, haluskan, dan beri sedikit air. Bungkus kunyit tersebut dengan kain putih, lalu diperas untuk memperoleh air kunyit. Larutan boraks dibuat dengan cara memasukkan sedikit boraks ke dalam beberapa sendok teh air (sesuai dengan kebutuhan). Campurkan lima tetes larutan kunyit dengan lima tetes larutan boraks. Aduk kedua larutan itu hingga rata dan berwarna merah kecoklatan. Larutan merah kecoklatan itu dapat dijadikan indikator adanya kandungan boraks dalam bahan makanan. Contoh makanan yang akan diuji ditumbuk hingga halus, dan diletakkan dalam cawan petri. Usahakan masing-masing bahan makanan tidak saling bercampur satu sama lain. Setelah itu bakar menggunakan bunsen. Perhatikan perbedaan yang terlihat dengan bahan kontrolnya.

Manfaat permainan: siswa mengenal perbedaan warna secara kasat mata. Mereka juga akan mengerti bagaimana cara mendeteksi awal makanan berbahaya dengan mudah.

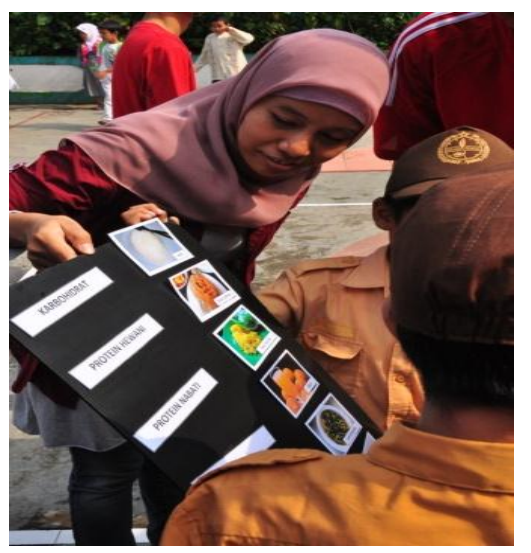

Gambar 4. Contoh Permainan untuk Edukasi Budaya Jajan Sehat

Untuk pelaksanaan kegiatan permainan, dibutuhkan sarana dan prasarana berupa: tempat berupa ruangan/ lapangan, perlengkapan permainan, dan tambahan hadiah bagi para pemenang. Para mahasiswa akan bertindak sebagai fasilitator yang memandu siswasiswi SD saat bermain. Setelah kegiatan berakhir, tim pelaksana PKM akan membagikan jajanan sehat yang terdiri dari kue, buah-buahan, dan minuman untuk disantap bersama atau dibawa pulang.

\section{SIMPULAN}

Artikel ini merupakan kajian sementara mengenai situasi dan kondisi yang akan dihadapi dalam kegiatan PKM mengenai edukasi pangan dan budaya jajan sehat di lingkungan SD Jatinangor. Alasan pemilihan lokasi kegiatan didasari pertimbangan kedekatan wilayah dengan kampus Universitas Padjadjaran dan urgensi atas pengentasan permasalahan yang telah ditemukan.

Pelaksanaan kegiatan diharapkan dapat berjalan lancar sesuai rencana, agar menambah pengetahuan dan mengubah perilaku serta budaya jajan siswa-siswi SDN Jatinangor menjadi lebih baik dan sehat. Metode penyuluhan dianggap cocok karena dapat merangsang aspek kognitif khalayak sasaran, sedangkan metode permainan relevan untuk diaplikasikan mengingat khalayak sasaran kegiatan ini adalah anak-anak.

Sebagai hasil dari kajian sementara ini, terungkap bahwa jajanan tradisional dianggap lebih sehat karena mengandung bahan-bahan alami yang mudah ditemukan sehingga harganya relatif murah dan tidak mengandung zat pengawet. Perhatian orang tua dan sekolah terhadap budaya jajan anak-anak sangat diperlukan, karena mereka masih sangat membutuhkan bimbingan dan pengarahan orang dewasa. Konsep nilai yang baik dan benar harus diajarkan sejak dini, karena akan turut menentukan perkembangan hidup mereka kelak. 
Available online at https://jurnal.stmikroyal.ac.id/index.php/jurdimas

\section{DAFTAR PUSTAKA}

Bryawan, Dodik. (2016). Perubahan Pengetahuan, Sikap, dan Praktik Jajanan Anak Sekolah Dasar Peserta Program Edukasi Pangan Jajanan. Jurnal Gizi Pangan.Vol.11 No.3. 201-210.

Febryanto, Mukhammad A.B. (2016). Hubungan Antara Pengetahuan dan Sikap dengan Perilaku Konsumsi Jajanan di MI Sulaimaniyah Jombang. Jurnal Keperawatan Muhammadiyah. Vol.1 No.1. 7-17.

Data Pokok Pendidikan Dasar dan Menengah. (2019). SD Negeri Jatinangor. http://dapo.dikdasmen.kemdikbud.go.i
d/sekolah/C819575773A84FB827EC diakses tanggal 18 Juli 2019

Hastutik \& Putri, N. Kadek S.K. (2018). Deskripsi Kebiasaan Jajan Pada Anak Sekolah Dasar Negeri 03 Kragilan Mojolaban Sukoharjo. Jurnal Ilmu Keperawatan dan Kebidanan. Vol.9 No.2. 162-167

Judarwanto, W. (2008). Perilaku Makan Anak Sekolah. http;//www.gizi.net/cgibin/berita/fullnews diakses tanggal 19 Juli 2019. 